\title{
Ocorrências éticas com profissionais de enfermagem: um estudo quantitativo
}

\author{
ETHICAL OCCURRENCES INVOLVING NURSING STAFF AND PROFESSIONALS: \\ AQUANTITATIVE APPROACH
}

OCURRENCIAS ÉTICAS CON PROFESIONALES DE ENFERMERÍA: UN ESTUDIO CUANTITATIVO

\author{
Genival Fernandes de Freitas' ${ }^{1}$, Taka Oguisso²
}

\section{RESUMO}

Este trabalho teve por objetivo identificar as características das ocorrências éticas, envolvendo a assistência de enfermagem, em um hospital particular de grande porte do município de São Paulo. Houve 190 ocorrências comunicadas à Comissão de Ética de Enfermagem (CEE) da Instituição, entre 1995 e 2004. Na maioria das ocorrências éticas não houve dano ao paciente, nem à Instituição de saúde ou ao profissional envolvido. Do total de 398 providências tomadas, em $94,5 \%$ dos casos foram de orientações dadas pela CEE aos profissionais de enfermagem, destacandose também orientações feitas pela chefia imediata deles. Em 93,7\% das ocorrências, envolvia apenas um profissional. As unidades de internação constituíram o cenário para $76,3 \%$ das ocorrências éticas. Como resultado, pode-se mencionar que o estudo demonstrou a importância da orientação aos profissionais, para prevenir ocorrências danosas à clientela.

\section{DESCRITORES}

Ética de enfermagem.

Cuidados de enfermagem.

Hospitais.

\begin{abstract}
This study aimed at identifying characteristics of ethical occurrences related to nursing care in a large private hospital in the city of São Paulo. There were 190 occurrences reported to the hospital's Nursing Ethical Committee (NEC) between 1995 and 2004. Most occurrences caused no damages to the patient, the health institution, the nursing staff or the professional involved. From the total of 398 procedures taken, $94.5 \%$ of the cases were advices given to nursing staff members by the NEC, including advice from the immediate superiors to the staff members involved. In $93.7 \%$ of the occurrences only one staff member was involved. Clinical units accounted for $76.3 \%$ of the services involved with ethical occurrences. As a result, it may be said that the study showed the importance of giving advices to the staff in order to prevent customers from damaging occurrences.
\end{abstract}

\section{KEY WORDS}

Ethics, nursing.

Nursing care.

Hospitals.

\section{RESUMEN}

En este trabajo se tuvo como objetivo identificar las características de las ocurrencias éticas, que involucran la asistencia de enfermería, en un hospital particular de gran porte del municipio de Sao Paulo. Hubo 190 ocurrencias comunicadas a la Comisión de Ética de Enfermería (CEE) de la Institución, entre 1995 y el 2004. En la mayoría de las ocurrencias éticas no hubo daño al paciente, ni a la Institución de salud o al profesional involucrado. Del total de 398 providencias tomadas, en el $94,5 \%$ de los casos fueron de orientaciones dadas por la CEE a los profesionales de enfermería, destacándose también las orientaciones realizadas por la jefatura inmediata de los mismos. El 93,7\% de las ocurrencias, involucraba apenas a un profesional. Las unidades de internamiento constituyeron el escenario para $76.3 \%$ de las ocurrencias. Como resultado se puede decir que el estudio ha demostrado la importancia de las orientaciones a los profesionales para prevenir ocurrencias dañinas para los pacientes.

\section{DESCRIPTORES}

Ética de enfermería. Atención de enfermería. Hospitales.

${ }^{1}$ Enfermeiro. Professor Doutor do Departamento de Orientação Profissional da Escola de Enfermagem, Universidade de São Paulo (EEUSP). São Paulo, SP, Brasil. genivalf@usp.br 2 Enfermeira. Advogada. Professora Titular do Departamento de Orientação Profissional da Escola de Enfermagem, Universidade de São Paulo (EEUSP). São Paulo, SP, Brasil. takaoguisso@usp.br 


\section{INTRODUÇÃO}

A Enfermagem vem se desenvolvendo com base em conhecimentos empíricos e teóricos fundamentados em múltiplas atividades profissionais voltadas para a assistência, o ensino, o gerenciamento e a pesquisa. Nesse desenvolvimento da profissão, é levado em conta o processo de trabalho da equipe de enfermagem, porquanto esse processo visa propiciar ações de cuidar de forma segura. Sendo assim, além da habilidade técnica, é imprescindível que os profissionais de enfermagem também detenham conhecimentos a respeito das normas regulamentadoras do exercício, dos direitos e das obrigações profissionais. Contudo, esse conhecimento não deve substituir as dimensões ética e moral que permeiam as ações desses profissionais.

Do ponto de vista ético, é esperado que o enfermeiro utilize sua criatividade ao gerenciar as ações assistenciais, ao tomar decisões e ao adequar os recursos humanos e materiais de que dispõe, assegurando um atendimento das necessidades dos pacientes com isenção de riscos, quando estes forem previsíveis e, portanto, passíveis de prevenção.

A previsibilidade é a possibilidade de ser antevisto o resultado nas condições em que o sujeito se encontrava no momento da realização de uma determinada ação. Assim, só há culpa profissional quando se puder estabelecer que o fato era possível de ser previsto pela perspicácia comum, normal dos homens. A previsibilidade deve, portanto, ser estabelecida também conforme a capacidade de previsão de cada indivíduo. Desse modo, o dever objetivo de cuidado é dirigido a todos, de se comportarem adequadamente, não se podendo exigir que as pessoas ajam desconfiando do comportamento de seus semeIhantes $^{(1)}$. Nessa ótica, os profissionais de enfermagem devem zelar pela segurança e integridade do paciente, prevendo situações que o exponham a riscos previsíveis, conforme estipulado no próprio Código de Ética dos Profissionais de Enfermagem, ao tratar das responsabilidades e dos deveres: Assegurar uma assistência de enfermagem livre de danos decorrentes de imperícia, negligência ou imprudência (art. 16) e no art. 33: Proteger o cliente contra danos decorrentes de imperícia, negligência ou imprudência por parte de qualquer membro da equipe de saúde $e^{(2)}$.

As ações dos profissionais de enfermagem devem fundamentar-se nos valores da profissão e no Código de Ética dos profissionais de enfermagem, assegurando a promoção, proteção, recuperação da saúde e reabilitação das pessoas, respeitando os preceitos éticos e legais. Assim, os princípios e valores éticos devem nortear as nossas decisões na condução das atividades diárias, enquanto profissionais, ao mesmo tempo em que tais va- lores nos oferecem uma estrutura para dar suporte à nossa autonomia(3).

$\mathrm{O}$ paciente tem o direito de ser informado sobre riscos, custos e benefícios das ações de saúde propostas. Dentre esses direitos do paciente, destacam-se o de ter assegurado uma assistência de enfermagem isenta de riscos ou de danos decorrentes de falhas ou erros no agir profissional, quando essas suas atitudes revelam-se negligentes, imprudentes ou mesmo provocadas por falta de conhecimento ou habilidade ${ }^{(4)}$.

Contudo, uma atitude imprudente não está necessariamente vinculada à imperícia ou à negligência. Assim, o profissional poderá agir de forma culposa quando, mesmo não almejando obter um resultado prejudicial ao paciente, age de tal forma que esse resultado ocorra. No entanto, falhas ou erros que são acarretados por deficiências técnicas ou falta de conhecimento - por exemplo, quando o profissional não possui habilidade, conhecimento ou segurança para a realização de um determinado procedimento - podem ser acompanhados de imprudência ou mesmo negligência.

O tipo de falha técnica mais freqüentemente observado no dia-a-dia dos profissionais de enfermagem refere-se ao preparo e à administração de medicamentos, destacando-se a negligência como a principal causa de ocorrências desse tipo de falha, que pode redundar em alguma forma de prejuízo ao paciente, inclusive expondo-o seriamente a situações de perigo iminente de vida, mesmo não havendo a intencionalidade do profissional de acarretar esse perigo ${ }^{(5)}$.

A negligência consiste na falta de atenção ou inação; a imperícia decorre da inabilidade ou deficiente destreza; a imprudência caracteriza-se por uma atitude açodada ou precipitada ${ }^{(5)}$.

Em geral, quando uma pessoa age de forma culposa, ela não almeja causar um malefício a alguém, no entanto devido à sua falta de atenção, de destreza, de conhecimento ou devido à imprudência, o seu agir poderá resultar em risco a alguém, podendo tais riscos ser evitados ${ }^{(6)}$.

Nesse sentido, a Lei do Exercício Profissional de Enfermagem (LEPE) n.o 7.498, de 25 de junho de 1986, estabelece as competências dos profissionais de enfermagem e se constitui em uma forma de se aferir a responsabilidade no agir do profissional com base nas competências técnicas, éticas, políticas ou relacionais de cada um. De acordo com essa legislação, cabe ao enfermeiro o gerenciamento das ações de enfermagem, por meio da sistematização da assistência, ao planejar, executar, avaliar e discutir os resultados das condutas de enfermagem propostas com a sua equipe. Ainda, de acordo com essa legislação, o enfermeiro poderá delegar determinadas atri- 
buições ao técnico ou ao auxiliar de enfermagem, sob sua supervisão, quando não se tratar de ações privativas do enfermeiro ${ }^{(7)}$.

De acordo com essa lei, delegar atividades de enfermagem não implica, necessariamente, eximir-se da responsabilidade pelo fato de tê-las delegado. Ao enfermeiro compete avaliar a competência dos demais membros da sua equipe e somente delegar algo quando o profissional a quem se está delegando for competente, legal e tecnicamente, para o desempenho seguro da atividade delegada em relação ao paciente, evitando com essa atitude que o paciente sofra qualquer tipo de dano devido uma decisão precipitada ou sem a devida avaliação dos riscos que envolvem a atividade delegada.

Quanto às atribuições legais dos profissionais de enfermagem, destacam-se as atividades no preparo e na administração de medicamentos. Nesse sentido, observa-se que o exercício dessas atividades está sendo praticado, na maioria das instituições de saúde, por técnicos e auxiliares de enfermagem sob a supervisão do enfermeiro(8).

A administração de medicamentos aos pacientes adultos hospitalizados é atribuição do enfermeiro e da equipe de enfermagem a ele subordinada, sendo uma das maiores responsabilidades do seu exercício profissional(9).

A responsabilidade profissional consiste no ato de responder pelos próprios atos ou pelos atos de outrem sempre que destes resultarem prejuízo ou dano a terceiros protegidos por Lei ${ }^{(10)}$.

O controle, a previsão e a atuação do enfermeiro nas ocorrências éticas envolvendo os profissionais de enfermagem perpassam as ações gerenciais desse profissional, como líder da equipe de enfermagem e responsável pela supervisão e capacitação de recursos humanos em enfermagem. Assim, o enfermeiro torna-se responsável pelas ações de enfermagem, ao executá-las ou delegá-las a quem de direito na equipe de enfermagem.

Entende-se por ocorrências éticas de enfermagem os eventos danosos causados por profissionais de enfermagem no exercício de sua função, e têm a ver com atitudes inadequadas face ao colega de trabalho, à clientela ou à instituição em que trabalha. Esses eventos podem ser conseqüentes de atitudes de falta de atenção, de habilidades/ conhecimentos técnicos, ou falta de zelo ou prudência do profissional responsável por esses eventos, ou quando o profissional deixa de fazer uma ação esperada e com isso acarreta uma situação de risco ou de prejuízo a outrem ${ }^{(11)}$.

Tais ocorrências éticas não se limitam às falhas técnicas, mas podem envolver falhas relacionadas à atitude do profissional de enfermagem no que tange ao relacionamento, à comunicação e ao respeito entre o profissional e o paciente, ou entre os profissionais. No que se refere às informações prestadas aos pacientes sobre benefí- cios, riscos e conseqüências da assistência de enfermagem, tais informações não têm sido efetuadas de forma satisfatória, impossibilitando, muitas vezes, a escolha do paciente a respeito de sua saúde, o que pode refletir que a comunicação entre os profissionais de enfermagem e os pacientes não está sendo feita de modo efetivo, como um instrumento básico no exercício da enfermagem ${ }^{(12)}$.

De acordo com as normas ético-legais vigentes no exercício da enfermagem, cabe ao enfermeiro avaliar, criteriosamente, os riscos a que os pacientes encontram-se expostos, devendo informar a quem de direito sobre a existência desses riscos, a fim de preveni-los, por meio de ações educativas que envolvam as políticas das instituições de saúde e o compromisso de todos com as medidas preventivas dessas ocorrências. Nessa ótica, três hipóteses são elencadas como motivos para que iatrogenias possam ocorrer no processo de cuidar: quando a demanda do sistema é maior do que a performance de quem cuida, isto é, quando o profissional está sujeito a uma sobrecarga de entradas (solicitações, informações) maior do que é capaz de processar; quando existe uma queda ou baixo desempenho profissional do indivíduo que presta assistência direta ao paciente (devido ao despreparo técnico do profissional ou grau de fadiga ou cansaço por parte do profissional) ou quando existe a combinação desses dois fatores anteriores ${ }^{(13)}$.

\section{OBJETIVOS DO ESTUDO}

O objetivo deste estudo foi identificar algumas características das ocorrências éticas relacionadas aos danos causados à clientela, à instituição e aos profissionais envolvidos e as orientações feitas pelas chefias imediatas e pela Comissão de Ética de Enfermagem (CEE) aos profissionais envolvidos, bem como os setores das ocorrências e o quantitativo de pessoas envolvidas nas mesmas, em um hospital particular do Município de São Paulo, no período de 1995 a 2004.

\section{MÉTODO}

Trata-se de um estudo descritivo, exploratório e retrospectivo, de abordagem quantitativa, utilizando-se como referencial metodológico os conceitos de pesquisa quantitativa propostos por alguns autores ${ }^{(14-15)}$.

O presente estudo foi desenvolvido por meio de levantamento de um total de 190 ocorrências éticas com profissionais de enfermagem de um estabelecimento de saúde do Município de São Paulo, no período de janeiro de 1995 a junho de 2004, o qual dispõe de uma CEE, desde 1992 . O estudo foi realizado após o parecer favorável do Comitê de Ética em Pesquisa da instituição-alvo do estudo (Processo n. 09/04) e resultou, em parte, da dissertação de mestrado e da tese de doutoramento do autor principal. 
A coleta de dados se deu nos registros da CEE da instituição e foi utilizado um formulário, previamente elaborado, no qual constavam dados sobre o tipo de dano causado ao paciente/cliente, prejuízos à instituição e ao profissional, providências tomadas em relação ao profissional envolvido na ocorrência, orientações da chefia imediata ao profissional envolvido, número de profissionais envolvidos em cada ocorrência e os setores envolvidos. Os registros da CEE consistiam em: a) encaminhamento da ocorrência em um formulário com informações sobre o dia, a hora, o local, o nome do profissional envolvido e a descrição dos fatos; b) livros de sindicância ética, que possuem relatórios de depoimentos de testemunhas ou dos próprios envolvidos; c) pareceres de sindicâncias, nos quais são orientados os profissionais envolvidos, após terem sido caracterizadas as ocorrências, o tipo de falha cometida e as providências tomadas em cada caso, em relação ao profissional, à chefia imediata e aos encaminhamentos realizados.

Do protocolo de encaminhamento, registros de sindicâncias e pareceres éticos da CEE foram obtidos os dados sobre a ocorrência, como dia e hora, suas causas, tipo de danos causados, se houve danos à instituição ou ao próprio profissional envolvido, tipo de providências tomadas, condutas das chefias imediatas, número de profissionais por ocorrência e os setores mais comuns onde tais eventos foram detectados.

Foram levados também em consideração pela CEE, a fim de elaborar um parecer para cada caso e orientar o profissional envolvido na ocorrência, o tipo de erro (falha técnica ou falha na conduta profissional), o dano ou o risco de dano ou prejuízo acarretado pela falha profissional.

A análise descritiva e quantitativa foi feita sobre as seguintes variáveis: possíveis danos ou prejuízos causados ao paciente, à instituição, ou ao próprio profissional envolvido, providências administrativas ou orientações dadas pela CEE ou pelas respectivas chefias imediatas dos profissionais envolvidos nas ocorrências, assim como o número de profissionais por ocorrência e os setores envolvidos.

\section{RESULTADOS}

O presente estudo foi desenvolvido em um estabelecimento de saúde privado do Município de São Paulo, com mais de duzentos leitos e que possui um corpo clínico aberto. $O$ referido estabelecimento tem um perfil eminentemente cirúrgico e a clientela atendida, na sua maioria (em torno de $75 \%$ ), é conveniada a seguradoras de saúde.

No período da realização desse estudo, a força de trabalho da equipe de enfermagem no local estudado era composta, aproximadamente, de $35 \%$ de enfermeiros, $23 \%$ técnicos de enfermagem e $42 \%$ de auxiliares de enfermagem no período de 1995 a 2004.
Em relação às ocorrências éticas encaminhadas à CEE da instituição alvo do estudo, voltamo-nos para algumas de suas características, em relação ao tipo de danos causados ao cliente, ao tipo de prejuízo que sofreu a instituição e o profissional, providências, orientações aos envolvidos, bem como número de profissionais que cometeram tais ocorrências e os setores envolvidos.

Cabe, ainda, esclarecer que apenas algumas ocorrências éticas são encaminhadas à CEE da instituição, porque os enfermeiros-chefes decidem quais dessas ocorrências serão encaminhadas à CEE a partir do julgamento de sua relevância. Esse critério de relevância é estipulado pela própria CEE da instituição, em parceria com esses enfermeiros, sendo considerado que a ocorrência é relevante quando há alguma forma de prejuízo ao paciente, à instituição e aos profissionais de saúde envolvidos.

Tabela 1 - Distribuição das ocorrências segundo danos causados ao paciente - São Paulo - 2005

\begin{tabular}{lcc}
\hline Danos ao paciente & Freqüência & $\mathbf{\%}$ \\
\hline Não houve indicação de dano & 99 & 52,1 \\
Houve dano físico & 77 & 40,5 \\
Houve dano moral & 14 & 7,4 \\
Houve dano material & 0 & 0,0 \\
\hline Total & $\mathbf{1 9 0}$ & $\mathbf{1 0 0 , 0}$ \\
\hline
\end{tabular}

A Tabela 1 nos mostra que em $52,1 \%$, de um total de 190 ocorrências éticas encaminhadas à CEE do hospital-alvo do estudo, não houve indicação de qualquer tipo de dano ao paciente, ou seja, quem encaminhou a ocorrência à CEE e quem a avaliou nesse órgão não apontou qualquer prejuízo ao paciente. No entanto, o fato de ter sido aceita denúncia e instaurada uma sindicância ética para apurar os fatos envolvendo o profissional de enfermagem, já caracteriza um acontecimento relevante do ponto de vista da conduta ética esperada daquele profissional, muito embora não se tenha identificado dano ao paciente.

Convém esclarecer que alguns encaminhamentos à CEE referem-se a dificuldades no relacionamento entre os profissionais de enfermagem, como indisciplina, insubordinação, não se relacionando diretamente ao paciente. Desse modo, algumas ocorrências podem não estar envolvendo possibilidade de exposição do paciente a riscos de danos.

Talvez a forma como têm sido encaminhadas as ocorrências éticas à CEE não possibilite a identificação de danos aos pacientes. Nesse sentido, estudo anterior apontou que as denúncias nem sempre são devidamente formuladas, o que se torna um empecilho à apuração. Sendo assim, mecanismos eficientes de observação, supervisão e controle precisam ser bem definidos para que 
se possa identificar a infração ética, para que haja maior precisão na apuração e as informações auxiliem nas investigações ${ }^{(16)}$.

Parece que existe um certo tabu em se definir dano ao paciente e mais, ainda, em se identificar quais e quantos seriam esses danos. Assim, ao se encaminhar um profissional que cometeu uma determinada ocorrência à CEE, deve-se apontar qual foi a repercussão da sua conduta sobre a assistência de enfermagem, quando houver prejuízo ao paciente. Isso irá possibilitar que a CEE oriente esse profissional em relação à responsabilidade éticolegal que resulta de sua atitude e as implicações para ele e a instituição de saúde ${ }^{(17)}$.

Os dados da Tabela 1 nos revelam que em 40,5\% das ocorrências encaminhadas à CEE houve indicação de dano físico ao paciente. Em 7,4\% houve danos de ordem moral aos pacientes. Não houve indicação de dano material ao paciente. $\mathrm{O}$ dano físico relaciona-se à alguma forma de lesão corporal e pode ser causado pela ação ou pela omissão no cuidado, como hematomas, flebites e quedas ${ }^{(10)}$. 0 dano moral está ligado à ofensa a bens de ordem moral, tais como os que se referem à liberdade e à honra. Já o dano material, quando configurado, refere-se à perda ou ao prejuízo que fere diretamente um bem patrimonial, diminuindo o seu valor, restringindo a sua utilidade ou mesmo anulando-o ${ }^{(18)}$. Nas ocorrências éticas levantadas, houve dano físico ao paciente quando ocorreu flebite, hematoma ou escoriação devido à queda ou outro tipo de lesão corporal. Na ofensa moral, considerou-se que houve lesão dessa natureza, quando o paciente não foi informado sobre a ocorrência, embora o médico do paciente o tenha sido. O hospital, em geral, arca com as despesas decorrentes da falha cometida pelo profissional e, portanto, não houve indicação de dano material ao paciente.

Tabela 2 - Distribuição das ocorrências segundo os prejuízos causados à Instituição - São Paulo - 2005

\begin{tabular}{lcc}
\hline Prejuízo à instituição & Freqüência & \% \\
\hline Não houve indicação de dano à instituição & 167 & 87,9 \\
Houve dano patrimonial (material) & 23 & 12,1 \\
Houve dano moral & 0 & 0,0 \\
\hline Total & $\mathbf{1 9 0}$ & $\mathbf{1 0 0 , 0}$ \\
\hline
\end{tabular}

De acordo com a Tabela 2, em 12,1\% das ocorrências houve prejuízos de ordem patrimonial à empresa, a qual responsabilizou-se pelos custos de tratamentos, exames ou outros gastos pertinentes a falhas de profissionais de enfermagem. Em 87,9\% das ocorrências, não houve indicação de prejuízo à instituição. Por outro lado, no período analisado, em todas as ocorrências levantadas, não houve menção a danos morais em relação ao hospital. O dano moral em relação à empresa se caracterizaria se houvesse prejuízo à imagem da mesma perante a clientela ${ }^{(5)}$.
Tabela 3 - Distribuição das ocorrências, segundo prejuízo ao profissional envolvido na ocorrência - São Paulo - 2005

\begin{tabular}{lcc}
\hline Prejuízo ao profissional & Freqüência & \% \\
\hline Não houve prejuízo & 147 & $77,4 \%$ \\
Houve prejuízo moral & 42 & $22,1 \%$ \\
Houve prejuízo material & 1 & $0,5 \%$ \\
\hline Total & $\mathbf{1 9 0}$ & $\mathbf{1 0 0 , 0}$ \\
\hline
\end{tabular}

$\mathrm{Na}$ maioria das ocorrências, que foram levantadas neste estudo, conforme Tabela 3, não houve prejuízo ao profissional envolvido, com $77,4 \%$. No entanto, em $22,1 \%$ delas foi apontado prejuízo de ordem moral ao profissional. Nesse sentido, entende-se que este tipo de prejuízo se caracteriza por sofrimento, tristeza ou até depressão, por parte do próprio profissional envolvido na ocorrência, o qual pode se sentir responsável pelas conseqüências de seu erro e do dano causado ao paciente(5).

Talvez esse sofrimento do profissional seja também decorrente da instauração de uma sindicância, o que pode representar um processo penoso, tanto para seus membros quanto para os profissionais direta ou indiretamente envolvidos no fato em questão(19).

Tabela 4 - Distribuição das orientações e providências em relação aos profissionais de enfermagem envolvidos nas ocorrências éticas - São Paulo - 2005

\begin{tabular}{lcc}
\hline Providências tomadas & Freqüência & $\mathbf{\%}$ \\
\hline Orientações realizadas pela CEE & 376 & $94,5 \%$ \\
Providências administrativas & 22 & $5,5 \%$ \\
\hline Total & $\mathbf{3 9 8}$ & $\mathbf{1 0 0 , 0}$ \\
\hline
\end{tabular}

Em relação às providências tomadas após as ocorrências, verifica-se que o número de orientações realizadas supera o número de ocorrências, o que significa que, em um mesmo evento foram tomadas várias providências, sejam administrativas e/ou de orientação do profissional pela CEE. A Tabela 4 mostra que, entre as providências tomadas pela CEE, a orientação ao profissional envolvido no evento, foi a atividade preponderante em $94,5 \%$ dos casos. Por providências da CEE são entendidas: a instauração da sindicância ética para apuração dos fatos denunciados, o acompanhamento e encaminhamento do profissional ao setor de Educação Continuada para reciclagem ou aprimoramento de conhecimentos em áreas específicas, como técnicas de preparo e administração de drogas, por exemplo. As providências administrativas perfizeram um percentual de 5,5\% e consistiram em encaminhamentos à instância administrativa (como a gerência de enfermagem), a fim de que fossem tomadas as medidas cabíveis em relação a mudanças em estrutura física no setor da ocorrência, sugestões para estruturação do 
dimensionamento de pessoal por turno ou setor, ou outras condutas que dependiam da tomada de decisão e apoio da gerência de enfermagem.

Tabela 5 - Distribuição das condutas das chefias dos profissionais de enfermagem envolvidos nas ocorrências éticas - São Paulo - 2005

\begin{tabular}{lcc}
\hline Orientações da chefia imediata & Freqüência & $\mathbf{\%}$ \\
\hline $\begin{array}{l}\text { Orientação da chefia imediata ao profissional } \\
\text { sobre o motivo do encaminhamento à CEE }\end{array}$ & 245 & 99,2 \\
$\begin{array}{lcc}\text { Punição administrativa (advertência/suspensão } \\
\text { ou demissão) }\end{array}$ & 2 & 0,8 \\
\hline Total & $\mathbf{2 4 7}$ & $\mathbf{1 0 0 , 0}$ \\
\hline
\end{tabular}

De acordo com a Tabela 5, houve preocupação das chefias imediatas de enfermagem em orientar os profissionais envolvidos em ocorrências éticas sobre os motivos pelo quais os encaminhava à CEE. Assim, na maioria das ocorrências $(99,2 \%)$, os enfermeiros comunicaram aos profissionais envolvidos em tais eventos éticos, que os estariam encaminhando à CEE. Essa orientação por parte da chefia imediata atende aos princípios da ampla defesa e do contraditório, pois ao ser encaminhada determinada ocorrência para a CEE, o profissional envolvido tem tempo para articular sua defesa e preparar-se melhor para explicar o que aconteceu. Portanto, a maior parte dos enfermeiros que exercia função de chefia imediata no momento da ocorrência teve a preocupação de realizar orientações ao profissional, esclarecendo as causas do ocorrido e tomando providências no sentido de evitar novas ocorrências.

Tabela 6 - Distribuição das ocorrências, segundo o número de profissionais envolvidos - São Paulo - 2005

\begin{tabular}{lcc}
\hline $\mathbf{N .}^{\mathbf{0}}$ profissionais envolvidos & Freqüência & $\mathbf{\%}$ \\
\hline Um profissional & 178 & 93,7 \\
Dois profissionais & 8 & 4,2 \\
Três profissionais & 3 & 1,6 \\
Quatro profissionais & 1 & 0,5 \\
\hline Total & $\mathbf{1 9 0}$ & $\mathbf{1 0 0 , 0}$ \\
\hline
\end{tabular}

De acordo com a Tabela 6, a maior incidência de ocorrências éticas aconteceu com o envolvimento de apenas um profissional de enfermagem, com 93,7\% dos casos. Assim, de um total de 190 ocorrências encaminhadas à CEE, 8 delas, ou seja, 4,2\%, envolveram dois profissionais de enfermagem. Com três profissionais envolvidos, apenas 3 ocorrências, ou seja, 1,6\% e com quatro profissionais, apenas $0.5 \%$, ou seja, em apenas uma ocorrência existiram vários envolvidos ao mesmo tempo. Esse resultado mostra-nos que na maioria das vezes, o profissional erra sozinho e não em equipe. Também esse dado mostra que a responsabilidade individual prepondera sobre a responsabilidade conjunta, ou seja, de várias pessoas que provocam uma mesma falha.
Tabela 7 - Distribuição dos setores envolvidos nas ocorrências éticas - São Paulo - 2005

\begin{tabular}{lcc}
\hline SETOR & Freqüência & \% \\
\hline Unidade de internação & 145 & 76,3 \\
Pronto atendimento & 22 & 11,6 \\
Unidade de Terapia Intensiva & 15 & 7,9 \\
Centro Cirúrgico & 8 & 4,2 \\
\hline Total & $\mathbf{1 9 0}$ & $\mathbf{1 0 0 , 0}$ \\
\hline
\end{tabular}

Os dados da tabela acima mostram que a maioria das ocorrências éticas encaminhadas à CEE aconteceram nas unidades de internação, com $76,3 \%$ do total de casos. Em seguida, vêm o pronto atendimento com $11,6 \%$ e a unidade de terapia intensiva, com $7,9 \%$, respectivamente. Por último, o Centro Cirúrgico, com 4,2\% do total de encaminhamentos à CEE. Esses resultados são pertinentes com estudo anterior que apontou que a maioria das ocorrências são observadas nas unidades de internação porque é nessas áreas que o paciente tem uma permanência maior e a maior parte dos procedimentos de enfermagem é realizada $^{(5)}$.

\section{CONSIDERAÇÕES FINAIS}

Ao enfermeiro cabe avaliar, criteriosamente, os riscos a que os pacientes se encontram expostos, devendo informá-los sobre a existência desses riscos e os cuidados propostos para preveni-los, mas, sobretudo isentá-lo de ocorrências que lhes possam prejudicar e que estejam relacionadas à assistência de enfermagem, mediante ações educativas que envolvam o interesse de todos e que previnam essas ocorrências.

A falta de atenção pode ser um fator preponderante na causa de dano ao paciente, tendo como responsáveis os profissionais de saúde ou, particularmente, de enfermagem envolvidos em condutas caracterizadas como negligentes. Nessa perspectiva, a negligência, falhas individuais e problemas na administração de serviços constituem-se em importantes atributos das causas de erros, cometidos pelos profissionais de enfermagem, no que tange ao preparo e administração de medicamentos ${ }^{(20)}$.

A análise dos achados deste estudo revelou, ainda, o quanto é necessário que o enfermeiro avalie, cuidadosamente, os riscos da assistência e os danos que podem advir de situações previsíveis, como quedas ou falhas humanas. As ações educativas devem fazer parte das metas institucionais, e despertar o interesse de todos os profissionais, no sentido de prevenir que situações que demandem riscos à segurança e à integridade física e/ou moral do paciente ${ }^{(5)}$.

Assim, as orientações aos profissionais de enfermagem envolvidos em ocorrências éticas, devem possuir um caráter educativo e não punitivo, tanto por parte da che- 
fia imediata do profissional envolvido na ocorrência, quanto por parte da CEE, da gerência ou supervisão de enfermagem, possibilitando que o profissional envolvido possa exteriorizar seus sentimentos e a sua versão dos

\section{REFERÊNCIAS}

1. Tourinho FCF. Processo penal. São Paulo: Saraiva; 2003.

2. Conselho Federal de Enfermagem (COFEN). Resolução COFEN n. 240/2000. Aprova o Código de Ética dos Profissionais de Enfermagem e dá outras providências. In: Conselho Regional de Enfermagem de São Paulo (COREN$\mathrm{SP})$. Documentos básicos de enfermagem: enfermeiros, técnicos e auxiliares. São Paulo; 2001. p. 277-89.

3. Trevizan MA, Mendes IAC, Lourenço MR, Shinyashiki GT. Aspectos éticos na ação gerencial do enfermeiro. Rev Lat Am Enferm. 2002;10(1):85-9.

4. São Paulo (Estado). Lei n. 10.241, de 25 de março de 1999. Dispõe sobre os direitos dos usuários dos Serviços e das Ações de Saúde no Estado de São Paulo. Diário Oficial do Estado de São Paulo, 18 mar. 1999. Seção 51, p. 1.

5. Freitas GF. Ocorrências éticas com pessoal de enfermagem de um hospital do Município de São Paulo [dissertação]. São Paulo: Escola de Enfermagem, Universidade de São Paulo; 2002.

6. Mirabete JB. Manual de direito penal. São Paulo: Atlas; 2001.

7. Brasil. Lei n. 7.498, de 25 de junho de 1986. Dispõe sobre a regulamentação do exercício da enfermagem e dá outras providências. In: Conselho Regional de Enfermagem de São Paulo (COREN-SP). Documentos básicos de enfermagem: enfermeiros, técnicos e auxiliares. São Paulo; 2001. p. 36-41.

8. Coimbra JAH, Cassiani SHDB. Responsabilidade da enfermagem na administração de medicamentos: algumas reflexões para uma prática segura com qualidade de assistência. Rev Lat Am Enferm. 2001;9(2):56-60.

9. Laganá MTC, Araújo TL, Santos LCR, Silva SH. Princípios gerais de administração de medicamentos e ações de enfermagem. Rev Esc Enferm USP. 1989;23(1):3-16.

10. Oguisso T, Schmidt MJ. O exercício da enfermagem: uma abordagem ético-legal. São Paulo: LTr; 1999. fatos, a motivação da ocorrência, promovendo uma reflexão com o profissional que o capacite a superar suas próprias limitações ou dificuldades, bem como incentivando-o a aprimorar seus conhecimentos e habilidades ${ }^{(5)}$.

11. Freitas GF. Ocorrências éticas de enfermagem: uma abordagem compreensiva da ação social [tese]. São Paulo: Escola de Enfermagem, Universidade de São Paulo; 2005.

12. Ferreira MMTGB. Informações prestadas a clientes sobre benefícios, riscos e conseqüências da assistência de enfermagem: um estudo exploratório [dissertação]. São Paulo: Faculdade de Saúde Pública, Universidade de São Paulo; 1998.

13. Padilha KG. Iatrogenias em unidade de terapia intensiva: uma abordagem teórica. Rev Paul Enferm. 1992;11(2):69-72.

14. Gil AC. Métodos e técnicas de pesquisa social. São Paulo: Ática; 1994.

15. Goode WJ, Hatt PK. Métodos em pesquisa social. São Paulo: Nacional; 1997.

16. Mendes HWB, Caldas Junior AL. Infrações éticas envolvendo pessoal de enfermagem. Rev Lat Am Enferm. 1999;7(5):5-13.

17. Freitas GF, Oguisso T. Negligência: fator de risco no cuidar em Centro Cirúrgico. RECENF Rev Tecn Cient Enferm. 2003;1(3):224-7.

18. Silva DP. Vocabulário jurídico. Rio de Janeiro: Forense; 2004.

19. Melo MRAC. A Comissão de Ética de Enfermagem na visão do enfermeiro. Esc Anna Nery Rev Enferm. 2004;8(2):224-34.

20. Miasso Al, Grou CR, Cassiani SHB, Silva AEBC, Fakih FT. Erros de medicação: tipos, fatores causais e providências tomadas em quatro hospitais brasileiros. Rev Esc Enferm USP. 2006; 40(4):524-32. 